\title{
American pika (Ochotona princeps) population survival in winters with low or no snowpack
}

\author{
Andrew T. Smith ${ }^{1, *}$ and Constance I. Millar ${ }^{2}$ \\ ${ }^{1}$ School of Life Sciences, Arizona State University, Tempe, AZ 85287-4501 \\ ${ }^{2}$ USDA Forest Service, Pacific Southwest Research Station, Albany, CA 94710
}

\begin{abstract}
A prediction that has gained considerable traction in the American pika (Ochotona princeps) literature is that because of climate change, high mortality is likely to occur in winters of low or early snowmelt and cause extirpation of local populations. The basis for this prediction is the perception that the absence of an insulative layer of snow to protect pikas from severe winter cold temperatures may cause animals to utilize metabolic reserves through excessive thermoregulation before the spring emergence of fresh vegetation, or die directly from exposure to extreme winter temperatures. The Sierra Nevada of east central California experienced its lowest snowfall in recorded history during the winter of 2014/2015. We observed patch occupancy as a proxy for overwinter survivorship of American pikas in the Sierra Nevada during summer 2015 in comparison to baseline populations at the same sites during summer 2014. In summer 2015, pika presence was documented at 36 of 37 sites where pikas had been observed in summer 2014. Contrary to the low snowfall-high mortality prediction, there was no evidence that the nearly total lack of snow caused unusual overwinter mortality in Sierra Nevada pikas.
\end{abstract}

RESUMEN.-Una de las predicciones como respuesta al cambio climático que ha ganado atención considerable en la literatura sobre la pika americana (Ochotona princeps), es la que probablemente apunta a una alta mortalidad cuando los inviernos con poca o pronta etapa de deshielo, y causa que las poblaciones locales se exterminen. El fundamento de esta predicción es la percepción de la ausencia de una capa de aislamiento contra la nieve que protege a las pikas de inviernos severos con temperaturas frías lo que hace que los animales utilicen sus reservas metabólicas en procesos regulatorios térmicos antes de que emerja la vegetación fresca de la primavera, o que mueran directamente a la exposición de inviernos de temperaturas extremas. La Sierra Nevada del este de California evidenció la caída de nieve más pobre registrada en la historia durante el invierno del 2014/2015. Nosotros observamos una ocupación a manera de parches como un indicador de sobrevivencia a la temporada de invierno de las pikas americanas en la Sierra Nevada durante el año de 2015, en comparación con la línea base de las poblaciones en los mismos lugares durante el verano de 2014. En el verano del 2015, se documentó la presencia de pikas en 36 de 37 sitios donde las pikas fueron observadas durante el verano 2014. En contradicción a lo expuesto a ocurrir durante los inviernos con poca o pronta etapa de deshielo-alta mortalidad, no se encontraron evidencias en donde la casi total ausencia de nieve haya causado una mortalidad inusual después de la temporada de invierno en las pikas de la Sierra Nevada.

Formozov et al. (1964:108-122) highlighted the importance of snow cover as an insulative factor that improves the probability of overwinter survival of northern nonhibernating small mammals. Smith (1978) extended this argument in his discussion of factors leading to the evolution of litter size in American pikas (Ochotona princeps) by stating: “The relationship between adult mortality and date of spring snowmelt is unknown, and data elucidating this critical point will be difficult to obtain. However, mortality caused by an early snowmelt or a late snow cover should be more common in unpredictable than in predictable environments” (p. 137); and “... temporal unsaturation caused by high density-independent mortality in years of early or late snowmelt provided more vacant sites on each patch" (p. 138). This prediction has gained traction in the American pika literature, relating pika vulnerability to climate change and linking a lack of winter snow (Mote et al. 2005, Huss et al. 2017) to high density-independent mortality and local extirpations (e.g., Beever et al. 2010, Manning and Hagar 2011, Wilkening et al. 2011, Ray et al. 2012, Yandow et al. 2015). However, there are few direct data bearing on the relationship between low snowpack and

*Corresponding author: a.smith@asu.edu 
TABLE 1. Average and extreme snowpack data (snow water equivalents in centimeters on 1 April) at select sites in the central Sierra Nevada, as measured by the California Cooperative Snow Survey (CCSS).

\begin{tabular}{lccccrc}
\hline Station (CCSS code) & $\begin{array}{c}\text { Elevation } \\
(\mathrm{m})\end{array}$ & $\begin{array}{c}\text { Years } \\
\text { of record }\end{array}$ & $\begin{array}{c}\text { Average } \\
\text { depth }(\mathrm{cm})\end{array}$ & $\begin{array}{c}\text { Greatest } \\
\text { depth, year }\end{array}$ & $\begin{array}{c}\text { Lowest } \\
\text { depth, year }\end{array}$ & $\begin{array}{c}\text { 2nd lowest } \\
\text { depth, year }\end{array}$ \\
\hline Dana Meadows (157) & 2987 & 89 & 74.9 & $159.3,1983$ & $10.2,2015$ & $16.8,1977$ \\
Tioga Pass (181) & 2987 & 85 & 66.3 & $159.3,1983$ & $3.8,2015$ & $18.8,1977$ \\
Mono Pass (182) & 3490 & 58 & 75.4 & $167.1,1969$ & $12.7,2015$ & $20.1,1977$ \\
Mammoth Pass (205) & 2835 & 85 & 106.9 & $219.7,1969$ & $3.8,2015$ & $21.8,1977$ \\
Saddlebag Lake (287) & 2972 & 75 & 77.5 & $157.2,1983$ & $5.1,2015$ & $25.1,1977$ \\
Virginia Lakes Ridge (377) & 2835 & 47 & 47.5 & $111.0,1983$ & $6.4,2015$ & $15.0,1977$ \\
\hline
\end{tabular}

increased mortality in American pikas. Yandow et al. (2015) conducted an indirect before-andafter study using scat density as a proxy for pika occupancy and concluded that their findings weakly supported the low snowfall-high mortality prediction.

Here we present evidence bearing on the prediction that pika mortality increases during winters with low snowpack, capitalizing on the extreme drought conditions pikas experienced in California's Sierra Nevada during the winter of 2014/2015. We present the Sierra Nevada snowpack data from that winter, our observations of pika survivorship the following summer as well as summer 2016, and discuss additional variables that may have impacted the relationship of pika survival to winter snowpack.

\section{Methods}

\section{Sierra Nevada Snowpack}

The standard metric for determining water futures in the Intermountain West is the water content of snow on 1 April; this is the same metric used by Smith (1978) in his analysis of comparative demography of pikas throughout the Intermountain West. These data are gathered for the Sierra Nevada by the California Cooperative Snow Survey (http://cdec.water .ca.gov/snow/). For the winter of 2014/2015, water content of snow on 1 April 2015 was at a historic low-only $5 \%$ of the historic average (CDWR 2015, Belmecheri et al. 2016). Snowcourse data from the California Cooperative Snow Survey in the region where we work (the east central Sierra Nevada) ranged from $3.6 \%$ to $16.8 \%$ of average (Table 1). Farther south in the Sierra Nevada, no snow was recorded at the stations at Big Pine Creek (elevation 2987 masl), Rock Creek Lakes (2957 m asl), North Lake (2835 masl), or South Lake (2926 masl). California Governor Jerry
Brown visited one site near Echo Summit ( $2271 \mathrm{~m}$ asl) on 1 April 2015 where the average snow depth for that date was $169 \mathrm{~cm}$, and all he saw was bare ground with no snow in sight (Schlanger 2015). The previous low water content of snow on 1 April was approximately $25 \%$ of average, which occurred in both 1977 and 2014 (CDWR 2015, Belmecheri et al. 2016). In the east central Sierra Nevada, the second lowest recorded readings among all census years occurred in 1977 and ranged from $20.4 \%$ to $32.4 \%$ of average (Table 1 ).

\section{American Pika Survivorship}

We examined whether or not American pika mortality increases during winters with low snowpack by comparing our observations of pika occupancy in summer 2014 with observations from summer 2015, following the no-to-low snowpack winter of 2014/2015. We followed up by observing identified populations again in summer 2016.

The ideal method of examining the low snowfall-high mortality prediction would be to follow populations of individually marked pikas observed on their individual territories for a period of time during summer (e.g., Tapper 1973, Smith and Ivins 1984), followed by their identification (or noted absence) during the following summer. We do not have this gold standard, as we naturally could not foresee that the winter of $2014 / 2015$ would be such an outlier compared to all recent snow records in the Sierra Nevada. Our data include detailed observations made at widely dispersed but repeatedly observed sites in the east central Sierra Nevada during the summers of 2014, 2015 (37 sites), and 2016 (33 sites). Our goal is not to be comprehensive in the determination of a local population of pikas, but rather to contrast as accurately as possible a baseline of known active pika territories from summer 2014 with observations of 
these sites in summers 2015 and 2016. All site data were initially collected for other studies; the sites were not chosen as a subset of pikas perceived as more likely to survive the lowsnow winter of 2014/2015.

We determined that a site was occupied when by late summer we found a well-formed green haypile-the cache of vegetation that nonhibernating pikas gather during summer to serve as a source of food overwinter (Millar and Zwickel 1972, Conner 1983, Dearing 1997). Pikas are individually territorial, male and female territories are equivalent in size, and the haypile marks the center of activity within each territory (Tapper 1973, Smith and Ivins 1983a, 1984). At each site we also tallied direct observations of adult pikas (juveniles are easily discerned during their summer of birth by smaller size and gray pelage) and instances when we heard a pika's characteristic vocalization within its putative territory.

Repeat surveys of pika occupancy are robust because adults are long lived (in the Sierra Nevada, average annual adult mortality is $45 \%$, many pikas live to be 3 or 4 years old, and maximum recorded longevity is 6 years; Smith 1978) and almost exclusively philopatric (Tapper 1973, Smith and Ivins 1983a, 1984, Smith 1987, Peacock 1997). Furthermore, territory replacement following death of an adult is normally by philopatric young born in the previous summer (Tapper 1973, Smith and Ivins 1983a, Smith 1987, Peacock 1997); thus these individuals are indicative of overwinter survival at that site. Correspondingly, absence at a site most likely indicates an inability of pikas to survive there.

\section{RESUlTS}

We found no evidence for an unusual amount of mortality of pikas in the east central Sierra Nevada during the winter of 2014/2015 (Table 2). During summer 2015, we recorded active green haypiles at $89.2 \%(33 / 37)$ of the baseline sites examined in summer 2014. In 2015 we failed to find active green haypiles at only $12.5 \%(7 / 56)$ of the baseline haypiles located in 2014. Pikas were seen or heard at $78 \%$ (29/37) of sites in summer 2014 and $91 \%$ (30/37) of sites in summer 2015 (including at 3 of the 4 sites where we failed to record active green haypiles that year, indicative of survivorship there). Thus, in summer 2015, we failed to find active pika presence at only one of the 37 baseline sites (Ellery Lake, where 2 fresh haypiles had been recorded in summer 2014). We frequently observed massive haypiles in summer 2015 (Fig. 1), consistent with an interpretation that pikas were not stressed by conditions of the preceding winter.

Our identification of the presence of pikas during these years was conservative. There were large populations of pikas at most sites, but in most cases we focused on only a single or small number of well-known documented territories (Table 2). For example, we report a single territory to represent the Saddlebag Lake Westside Trail, but this trail extends for $1700 \mathrm{~m}$ along the western shore of the lake, and in summers 2014 and 2015, pikas were observed in the talus above and below the trail along its entire reach. Similarly, only 3 territories are reported for the Middle Gaylor Lake talus, whereas this site appeared nearly saturated (all territories occupied) with pikas to the east and upslope from these territories in both years. A single territory was chosen to represent the continuous talus slope east of the trail and stream leading up to Moat Lake, yet by our repeat observations the slope was saturated along its reach by pikas in both years.

Our primary analysis of the low snowpackhigh mortality prediction involves the comparison of pika populations between summers 2014 and 2015. Due to the possibility of a cumulative effect, whereby decreased fitness of long-lived pikas during the winter of 2014/2015 could carry over and be manifested in the following year, we also examined pika occupancy at most (33) of the baseline sites in summer 2016. The pattern of pika occupancy in 2016 was similar to the previous 2 summers. Green haypiles were found at $87.9 \%$ $(29 / 33)$ of sites. Three of the 4 sites without active haypiles in 2015 contained fresh green haypiles; only the Ellery Lake site remained unoccupied from 2014. Pikas were seen or heard at $75.8 \%(25 / 33)$ of the sites, including 3 of the 4 sites where we failed to find fresh green haypiles (Table 2).

\section{Discussion}

Although the winter snowpack of 2014/2015 was the lowest in recorded history in the Sierra Nevada, we found no pattern of increased mortality in the American pika, thus 


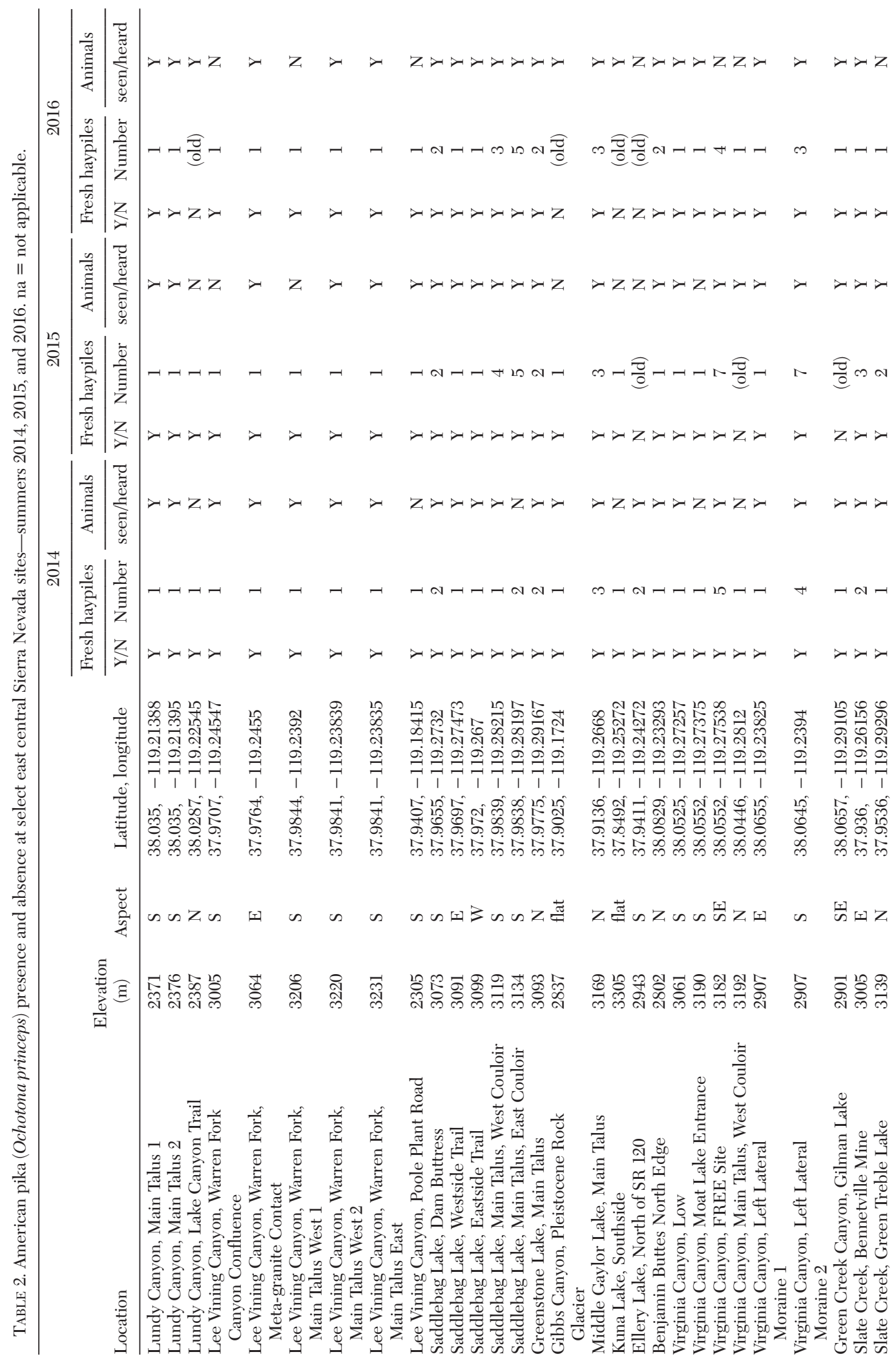




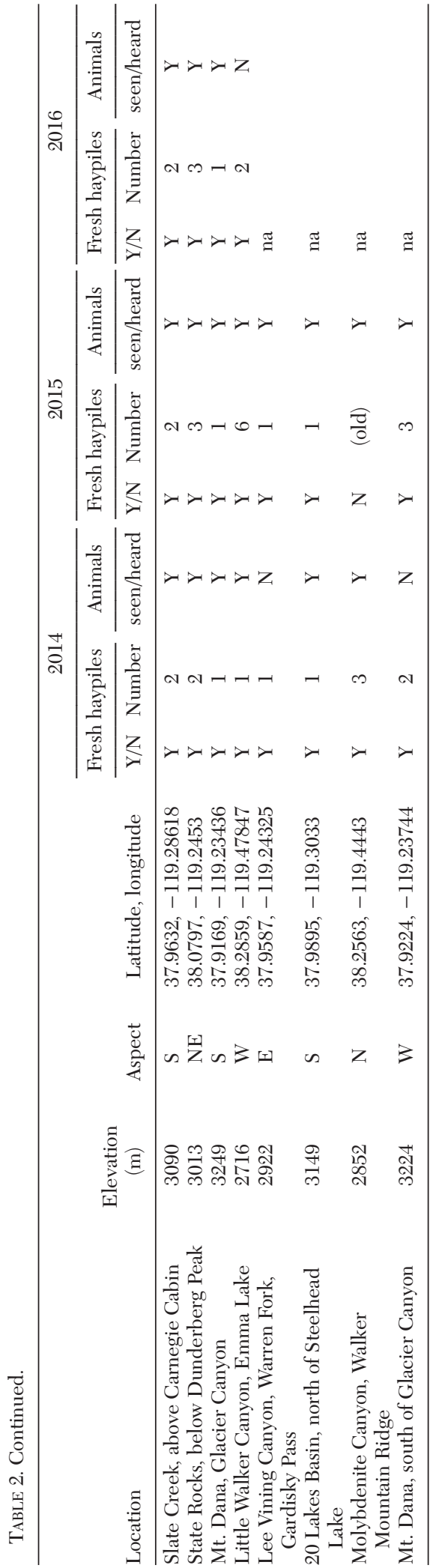

refuting the low snowpack-high mortality prediction. There are several nonexclusive reasons for this finding. Perhaps the most important is that recent analyses have shown that there is greater buffering of extreme temperatures provided by the talus habitat occupied by pikas than had been previously understood (Millar et al. 2013, 2014, 2016, Wilkening et al. 2015, Rodhouse et al. 2017). Rocky landforms, the habitat occupied by pikas, have thermal regimes shown to be highly decoupled from surface air measurements. This decoupling results in cooler subsurface temperatures with low variance during warm summer days and warmer temperatures under snow in cold winters (Millar et al. 2014, 2016). Even when snow cover is low or lacking, temperatures within the talus matrix during winter are significantly warmer than talus surface or free-air temperatures (Millar et al. 2016). Data from these prior studies largely originate from the same sites as utilized in this study (Table 2).

Historical patterns in pika occupancy may also have influenced our result. To be included in our survey, each baseline site had to initially show sign of modern pika occupancy. However, not only was the winter of 2014/2015 severe, it followed several extremely dry years with below-average snowpack. It is possible that sites with extreme cold-air pooling that could have affected pika survival had eliminated vulnerable pikas, leaving only sites where pikas were more likely to persist in the event of a no-snowpack winter. Nevertheless, we began observing many of the sites prior to the recent drought, and our data still show high survivorship across a broad swath of the east central Sierra Nevada.

In addition to the lack of winter snow in the Sierra Nevada during the winter of 2014/ 2015, another factor may have affected pika survivorship. Spring (May-July 2015) precipitation was the highest ever recorded for the region (Reis 2015), thus providing a kick-start for the growth of vegetation. Thus the effect of depleted physiological reserves as a result of the low-snowpack winter could have been offset by this flush of food, although these animals would still have had to survive through the extreme winter cold.

In spite of the heavy precipitation during spring 2015, some pikas could have still been challenged physiologically, having depleted their fat reserves over the low-snowpack 


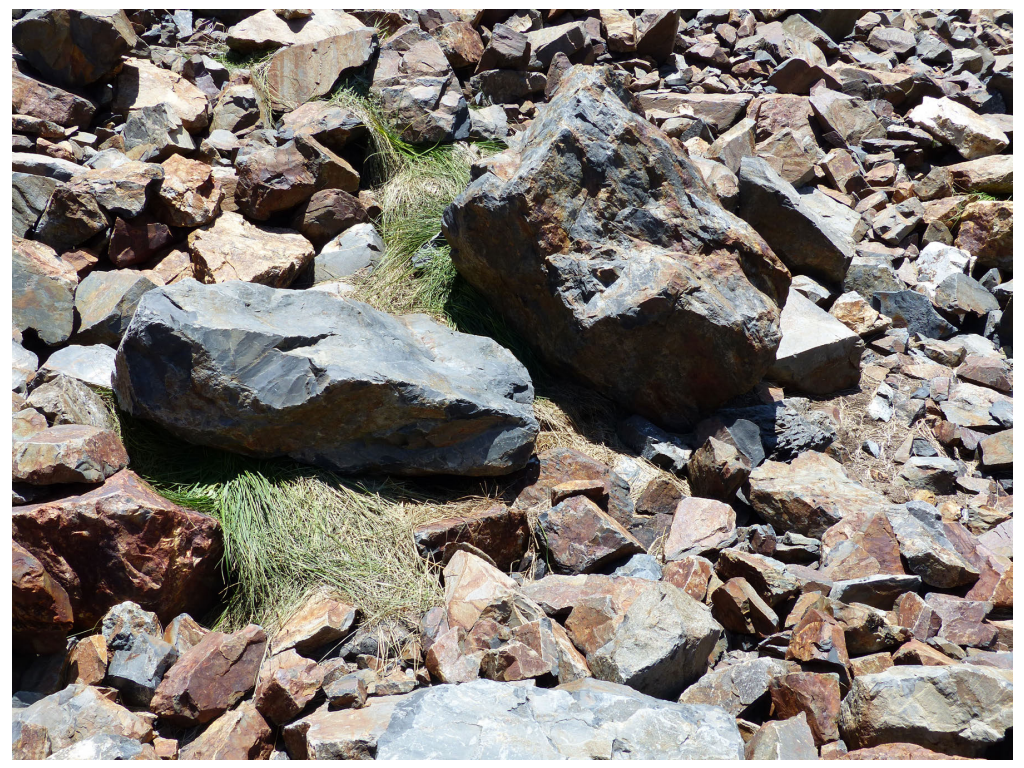

Fig. 1. Extensive haypile under construction on the talus leading to Moat Lake, summer 2015. Dried remains of haypiles gathered in previous summers can be seen extending from underneath the green vegetation gathered in 2015.

winter. This effect would have been evident had reproduction been delayed or curtailed. In normal years, female pikas put on weight prior to and even during gestation of their first litter to meet the demands of lactation following parturition (Millar 1973, 1974, Smith 1978, Smith and Ivins 1983b). Although pikas are long lived, a failure to reproduce during summer 2014 could have had a negative effect on pika populations during the following summers. For this reason, we continued to monitor our populations through summer 2016, but there were no noticeable downturns in pika populations that would point to such an event.

Last, although the winter snowpack of $2014 / 2015$ was essentially absent, winter temperatures during this period were above average (Belmecheri et al. 2016; Supplementary Material 1). Even with the lack of a layer of snow for thermal buffering, these warmer temperatures may have allowed the pikas to use less energy to maintain their thermal equilibrium. However, even when temperatures are above average in the Sierra Nevada, absolute (free-air) air temperatures in the high-elevation region where we censused pikas were still very cold (Supplementary Material 1c). Physiological responses of pikas when faced with temperatures far below freezing during winter in the field are unknown.
But the observed high overwinter survival indicates that American pikas may be far more resilient to extreme cold than has previously been appreciated.

In many ways biologists are in uncharted territory when attempting to evaluate how climate change may affect populations. The logic behind the low snowpack-high mortality prediction with regard to American pikas makes perfect sense. But it appears that American pikas, for whatever mechanism or reason, can survive winters with low or no snowpack.

\section{Supplementary Material}

One online-only supplementary file accompanies this article (https://scholarsarchive.byu .edu/wnan/vol78/iss2/2).

Supplementary Material 1. Comparison of long-term climate data for the east central Sierra Nevada with climate measures from winter $2014 / 2015$

\section{ACKNOWLEDGMENTS}

We thank Bob Westfall for assistance in the field and David Pearson and Harriet Smith for their conscientious reviews of an earlier draft of this manuscript. Alejandro Velázquez kindly translated the abstract into Spanish. 


\section{Literature Cited}

Beever, E.A., C. Ray, P.W. Mote, and J.L. Wilkening, 2010. Testing alternative models of climate-mediated extirpation. Ecological Applications 20:164-178.

Belmecheri, S., F. Babst, E.R. Wahl, D.W. Stahle, and V. Trouet. 2016. Multi-century evaluation of Sierra Nevada snowpack. Nature Climate Change 6(1):2-3.

[CDWR] California Department of Water Resources. 2015. Sierra Nevada snowpack is virtually gone; water content now only 5 percent of historic average, lowest since 1950. [Accessed 31 October 2016]. http://www.water.ca.gov/news/newsreleases/2015/04 0115snowsurvey.pdf

Conner, D.A. 1983. Seasonal changes in activity patterns and the adaptive value of haying in pikas (Ochotona princeps). Canadian Journal of Zoology 61:411-416.

DEARING, M.D. 1997. The function of haypiles of pikas (Ochotona princeps). Journal of Mammalogy 78: $1156-1163$.

Formozov, A.N., W. Prychodko, and W.O. Pruitt Jr. 1964. Snow cover as an integral factor of the environment and its importance in the ecology of mammals and birds. University of Alberta Press, Edmonton, Canada.

Huss, M., B. Bookhagen, C. Huggel, D. Jacobsen, R.S. Bradley, J.J. Clague, M. Vuille, W. Buytaert, D.R. Cayan, G. Greenwood, B.G. Mark, A.M. MilNER, R. WEINGaRTNER, AND M. Winder. 2017. Toward mountains without permanent snow and ice. Earth's Future 5. https://doi.org/10.1002/2016EF000514

Manning, T., and J.C. Hagar. 2011. Use of non-alpine anthropogenic habitats by American pikas (Ochotona princeps) in western Oregon. Western North American Naturalist 71:106-112.

Millar, C.I., R.D. Westfall, and D.L. Delany. 2013. Thermal and hydrologic attributes of rock glaciers and periglacial talus landforms: Sierra Nevada, California, USA. Quaternary International 310:169-180.

Millar, C.I., R.D. Westfall, and D.L. Delany. 2014. Thermal regimes and snowpack relations of periglacial talus slopes, Sierra Nevada, California, U.S.A. Arctic, Antarctic, and Alpine Research 46: 483-504.

Millar, C.I., R.D. Westfall, and D.L. Delany. 2016. Thermal components of American pika habitatHow does a small lagomorph encounter climate? Arctic, Antarctic, and Alpine Research 48:327-343.

Millar, J.S. 1973. Evolution of litter-size in the pika, Ochotona princeps (Richardson). Evolution 27: 134-143.

Millar, J.S. 1974. Success of reproduction in pikas, Ochotona princeps (Richardson). Journal of Mammalogy 55:527-542.

MillaR, J.S., AND F.C. ZwiCKEL. 1972. Characteristics and ecological significance of haypiles of pikas. Mammalia 36:58-68.

Mote, P.W., A.F. Hamlet, M.P. ClaRk, and D.P. LetTeNMAIER. 2005. Declining mountain snowpack in western North America. American Meteorological Society 86:39-49.

Peacock, M.M. 1997. Determining natal dispersal patterns in a population of North American pikas (Ochotona princeps) using direct mark-resight and indirect genetic methods. Behavioral Ecology 8:340-350.

Ray, C., E. Beever, and S. Loarie. 2012. Retreat of the American pika: up the mountain or into the void? Pages 245-270 in J.F. Brodie, E. Post, and D.F. Doak, editors, Wildlife conservation in a changing climate. University of Chicago Press, Chicago, IL.

REIS, G. 2015. Wettest May-July on record rescues Mono Lake from steeper decline. Mono Lake Newsletter 2015 (Fall): 12 .

Rodhouse, T.J., M. Hovland, and M.R. Jeffress. 2017. Variation in subsurface thermal characteristics of microrefuges used by range core and peripheral populations of the American pika (Ochotona princeps). Ecology and Evolution 7:1514-1526.

SChlanger, Z. 2015. Governor Brown orders first-ever California water cuts after seeing no snowpack. Newsweek; [accessed 31 October 2016]. http:// www.newsweek.com/gov-jerry-brown-orders-first -ever-california-water-cuts-after-seeing-complete $-318912$

Smith, A.T. 1978. Comparative demography of pikas (Ochotona): effect of spatial and temporal age-specific mortality. Ecology 59:133-139.

Sмiтh, A.T. 1987. Population structure of pikas: dispersal versus philopatry. Pages 128-142 in B.D. ChepkoSade and Z.T. Halpin, editors, Mammalian dispersal patterns: the effects of social structure on population genetics. University of Chicago Press, Chicago, IL.

SMith, A.T., AND B.L. Ivins. 1983a. Colonization in a pika population: dispersal versus philopatry. Behavioral Ecology and Sociobiology 13:37-47.

Smith, A.T., AND B.L. Ivins. 1983b. Reproductive tactics of pikas: why have two litters? Canadian Journal of Zoology 61:1551-1559.

Smith, A.T., AND B.L. Ivins. 1984. Spatial relationships and social organization in adult pikas: a facultatively monogamous mammal. Zeitschrift für Tierpsychologie 66:289-308.

TAPPER, S.C. 1973. The spatial organisation of pikas (Ochotona) and its effect on population recruitment. Doctoral dissertation, University of Alberta, Edmonton, Canada.

Wilkening, J.L., C. Ray, E.A. Beever, and P.F. BrusSARD. 2011. Modeling contemporary range retraction in Great Basin pikas (Ochotona princeps) using data on microclimate and microhabitat. Quaternary International 235:77-88.

Wilkening, J.L., C. Ray, and J. Varner. 2015. Relating sub-surface ice features to physiological stress in a climate sensitive mammal, the American pika (Ochotona princeps). PLOS ONE 10:e0119327.

Yandow, L.H., A.D. Chalfoun, AND D.F. DOAK. 2015. Climate tolerances and habitat requirements jointly shape the elevational distribution of the American pika (Ochotona princeps), with implications for climate change effects. PLOS ONE. https://doi.org/ 10.1371/journal.pone.0131082

Received 11 August 2017

Revised 13 February 2018

Accepted 26 February 2018

Published online 13 July 2018 